\title{
Effect of Liquid Ga on Metal Surfaces: Characterization of Morphology and Chemical Composition of Metals Heated in Liquid Ga
}

\author{
Eun Je Lee, Min Goo Hur, Jeong Mun Son, Jeong Hoon Park, and Seung Dae Yang \\ Radiation Instrumentation Research Division, Korea Atomic Energy Research Institute, 1266 Sinjeong-dong, Jeollabuk-do, \\ Jeongeup-si 580-185, Republic of Korea
}

Correspondence should be addressed to Min Goo Hur; hur09@kaeri.re.kr

Received 18 October 2012; Revised 21 December 2012; Accepted 21 December 2012

Academic Editor: Yue Li

Copyright (C) 2013 Eun Je Lee et al. This is an open access article distributed under the Creative Commons Attribution License, which permits unrestricted use, distribution, and reproduction in any medium, provided the original work is properly cited.

This study investigates the effect of liquid gallium (Ga) on metal foils made of titanium (Ti), niobium (Nb), and molybdenum (Mo). The Ti, Nb, and Mo foils were heated in liquid $\mathrm{Ga}$ at $120^{\circ} \mathrm{C}$ for a maximum of two weeks. After heating, the changes in the morphology and the chemical composition of the metal foils were analyzed by using a field emission scanning electron microscope, energy-dispersive X-ray spectrometer, X-ray diffractometer, and X-ray photoelectron spectrometer. The results of the analysis indicated that the $\mathrm{Nb}$ foil showed the minimum adhesion of liquid $\mathrm{Ga}$ to the surface while the maximum amount of liquid Ga was observed to adhere to the $\mathrm{Ti}$ foil. In addition, the $\mathrm{Nb}$ foil was oxidized and the Mo foil was reduced during the heating process. Considering these effects, we conclude that Mo may be used as an alternative encapsulation material for Ga in addition to $\mathrm{Nb}$, which is used as the conventional encapsulation material, due to its chemical resistance against oxidation in hot liquid Ga.

\section{Introduction}

${ }^{68} \mathrm{Ga}$ has attracted great attention in such medical research areas as positron emission tomography (PET) because it decays mainly via positron emission and has a short half-life ( $68 \mathrm{~min}$ ) [1]. Therefore, the production of ${ }^{68} \mathrm{Ge}$, the longlived (half-life of $\sim 288$ days) parent radioisotope of ${ }^{68} \mathrm{Ga}$, has become an important issue. ${ }^{68} \mathrm{Ge}$ can be produced by proton irradiation of a Ga target, or by alpha irradiation of a $\mathrm{Zn}$ target. However, the use of a $\mathrm{Zn}$ target induces difficulty in chemical processing after the irradiation because a third element $(\mathrm{Zn})$ is involved, and, thus, the use of a Ga target has attracted additional research interest. Various forms of $\mathrm{Ga}$, for example, $\mathrm{Ga}_{2} \mathrm{O}$ [1], $\mathrm{Ga}_{2} \mathrm{O}_{3}$ [2], $\mathrm{Ga}_{4} \mathrm{Ni}$ [3], and natural $\mathrm{Ga}$ [4] have been used for the production of ${ }^{68} \mathrm{Ge}$ by proton irradiation. Specifically, encapsulation is required when a natural $\mathrm{Ga}$ target is used because the natural $\mathrm{Ga}$ has relatively low melting point $\left(\sim 30^{\circ} \mathrm{C}\right)$ and is therefore easily liquefied by the temperature increase resulting from the bombardment of energetic protons. According to a report by Noriter et al., the maximum temperature produced in this process has been estimated to reach as high as $148^{\circ} \mathrm{C}$ in simulations under irradiation conditions of $29.5 \mathrm{MeV}$ in proton energy and $250 \mu \mathrm{A}$ in beam current [5]. When the encapsulation material is determined, its resistance to corrosion or embrittlement caused by liquid $\mathrm{Ga}$ is one of the most important criterion because the damage of encapsulation by liquid Ga during the proton irradiation can induce serious breakage of accelerator vacuum system. In this research, $\mathrm{Ti}$ and Mo were chosen as candidate encapsulation materials in addition to $\mathrm{Nb}$, the conventional choice for the encapsulation of $\mathrm{Ga}$ [4] because of the following reasons: $\mathrm{Ti}, \mathrm{Mo}$, and $\mathrm{Nb}$ are known to have satisfactory resistance to attack by $\mathrm{Ga}$ at temperatures up to $400^{\circ} \mathrm{C}$ [6]. Moreover, $\mathrm{Ti}$ is known to resist embrittlement by liquid $\mathrm{Ga}$ [7]. In addition, $\mathrm{Ti}$ and $\mathrm{Nb}$ are widely used metals in the ${ }^{18} \mathrm{O}$ water target for ${ }^{18} \mathrm{~F}$ production by proton irradiation because of their hardness and inertness [8], and Mo is used as a window material for the ${ }^{124}$ Xe target in ${ }^{123} \mathrm{I}$ production by proton irradiation [9]. Therefore, we could conclude that $\mathrm{Ti}$ and $\mathrm{Mo}$ are suitable candidate materials to this paper. Furthermore, a temperature of $120^{\circ} \mathrm{C}$ was chosen for the experiments; in our institute, we plan to produce ${ }^{68} \mathrm{Ge}$ 


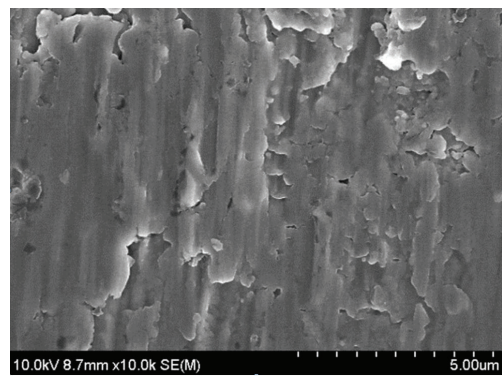

(a) pristine

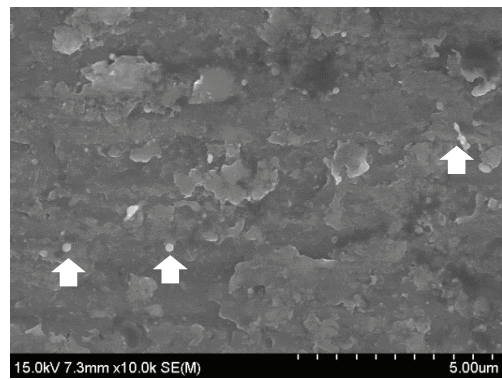

(d) 5 days

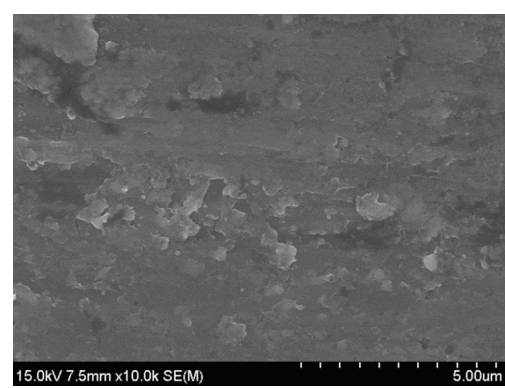

(b) 1 day

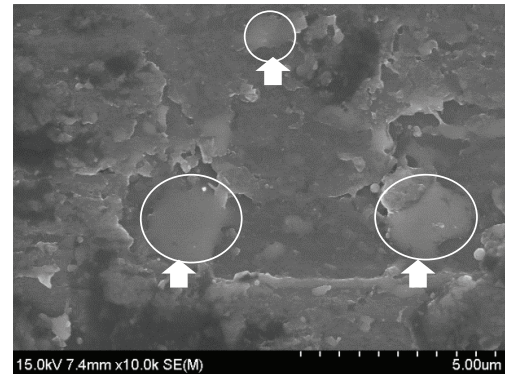

(e) 9 days

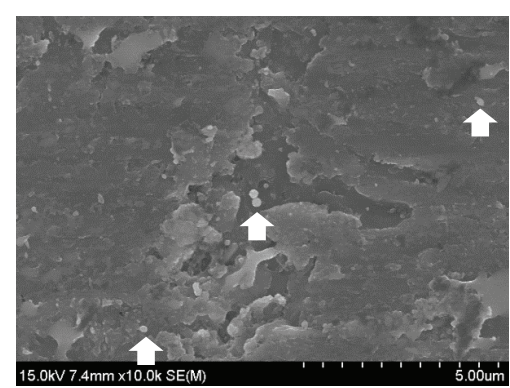

(c) 3 days

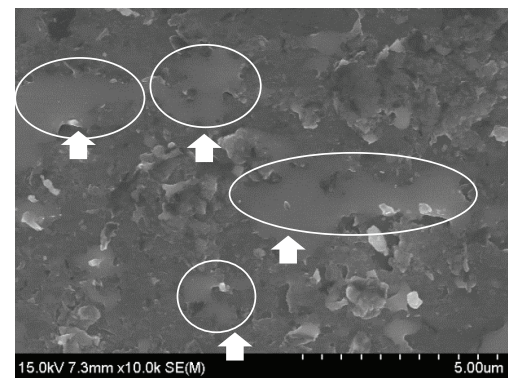

(f) 14 days

FIGURE 1: FESEM images of pristine Ti foil (a) and Ti foils heated in liquid Ga for 1 day (b), 3 days (c), 5 days (d), 9 days (e), and 14 days (f).

by proton irradiation with a $<200 \mu \mathrm{A}$ beam current, so we expect that the maximum temperature will not exceed $120^{\circ} \mathrm{C}$. To investigate whether Ti and Mo can be used as alternative materials to $\mathrm{Nb}$ in the $\mathrm{Ga}$ target for ${ }^{68} \mathrm{Ge}$ production, we carried out heating experiments with $\mathrm{Ti}, \mathrm{Nb}$, and Mo foils in liquid $\mathrm{Ga}$ at $120^{\circ} \mathrm{C}$ and investigated the effect of liquid $\mathrm{Ga}$ on the morphology and chemical composition of those metals in this paper. The amount of residual Ga after heating and washing was also measured because fine separation between $\mathrm{Ga}$ and an encapsulation material is important in real application.

\section{Experimental}

2.1. Material Preparation. Ga (Strategic Metal Investments, 99.9\%) was melted by heating at a temperature slightly above its melting point $\left(\sim 40^{\circ} \mathrm{C}\right)$. Next, $2 \mathrm{~mL}$ of $\mathrm{Ga}$ was transferred to each of several vials (Thermo Scientific ReactiVial number 13223). Ti (Goodfellow, thickness: $0.075 \mathrm{~mm}$, 99.6+\%), Nb (Goodfellow, thickness: $0.1 \mathrm{~mm}, 99.9 \%$ ), and Mo (Goodfellow, thickness: $0.05 \mathrm{~mm}, 99.9 \%$ ) foils were cut into samples with sizes of $5 \mathrm{~mm} \times 25 \mathrm{~mm}$ and dipped into the liquid $\mathrm{Ga}$ in the vials.

2.2. Heating Experiment. After the preparation of the vials containing liquid $\mathrm{Ga}$ and a sample of metal foils, the vials were placed on the heating device (Reacti-Therm Heating/Stirring Module, Thermo Scientific). The heating temperature was set to $120^{\circ} \mathrm{C}$, and the heating time was varied from 1 day to 14 days (Figure S1) (see Supplementary Material available online at http://dx.doi.org/10.1155/2013/619682). After the heating experiments, the metal foils were taken out of the vials and carefully washed with ethanol several times to remove any residual $\mathrm{Ga}$ on the metal foil surfaces. After washing, the samples were put into a vacuum oven and then dried at $40^{\circ} \mathrm{C}$ for 2 hours.

2.3. Characterization. The surface morphology of the metal foils heated in the liquid Ga was characterized with a field emission scanning electron microscope (FESEM, Hitachi S4800). Energy dispersive X-ray spectroscopy (EDS) analysis was carried out using a FESEM (Nova230, FEI) instrument equipped with an energy-dispersive X-ray spectrometer. The chemical compositions of the pristine and heated metal foils were investigated by X-ray photoelectron spectroscopy (XPS) using an $\mathrm{Mg}$ and $\mathrm{Al} \mathrm{K} \alpha \mathrm{X}$-ray source in a Sigma Probe (Thermo VG) spectrometer. The XPS spectra were curve fitted with a mixed Gaussian-Lorentzian shape using the XPSPEAK analysis software [10]. The Shirley function was used to remove the background prior to curve fitting. All of the XPS spectra were charge compensated to $\mathrm{C} 1 \mathrm{~s}$ at $285.0 \mathrm{eV}$. The crystallinity of the pristine and heated metal foils was examined with an X-ray diffractometer (XRD, RIGAKU, D/MAX-2500).

\section{Results and Discussion}

3.1. Surface Morphology. The surfaces of the $\mathrm{Ti}, \mathrm{Nb}$, and Mo foils were observed using FESEM. The surface of the pristine Ti foil appeared slightly rough, as shown in Figure 1(a). When the heating time of the Ti foil in the liquid Ga was increased, the amount of material adhered to the Ti foil was monotonically increased (Figures $1(\mathrm{~b})-1(\mathrm{f})$ ). The material that adhered to the surface of Ti foil was in the form of both nanoparticles with a size of several hundred $\mathrm{nm}$ 


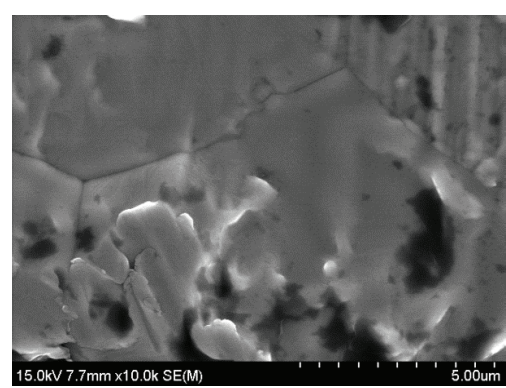

(a) Pristine

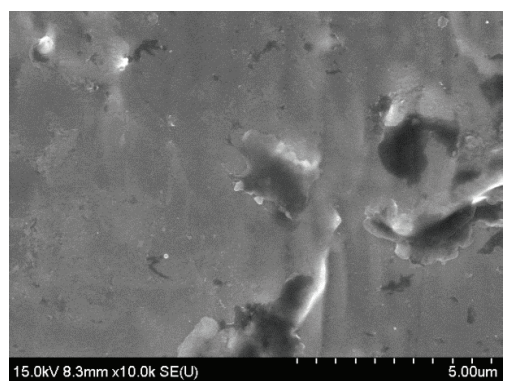

(d) 5 days

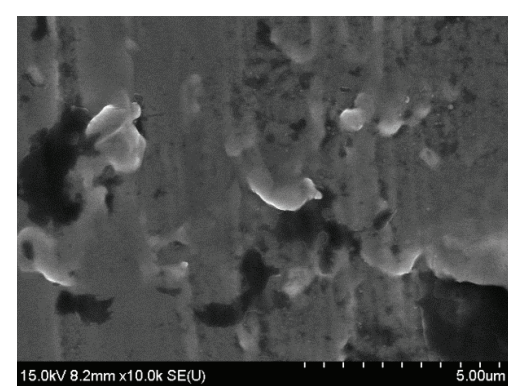

(b) 1 day

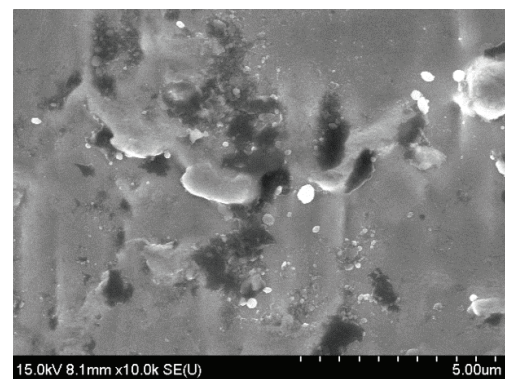

(e) 9 days

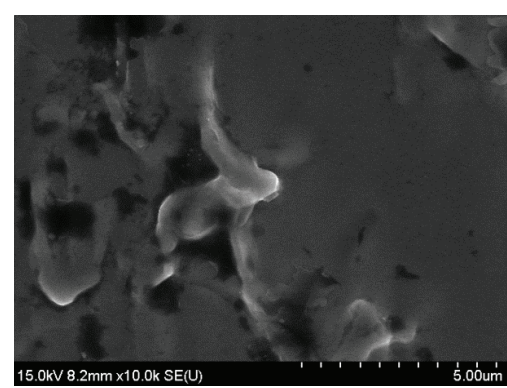

(c) 3 days

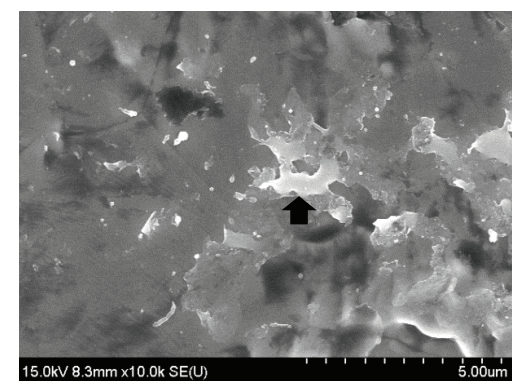

(f) 14 days

FIGURE 2: FESEM images of pristine $\mathrm{Nb}$ foil (a) and $\mathrm{Nb}$ foils heated in liquid Ga for 1 day (b), 3 days (c), 5 days (d), 9 days (e), and 14 days (f).

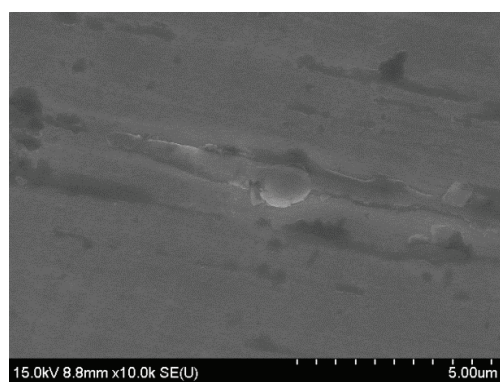

(a) Pristine

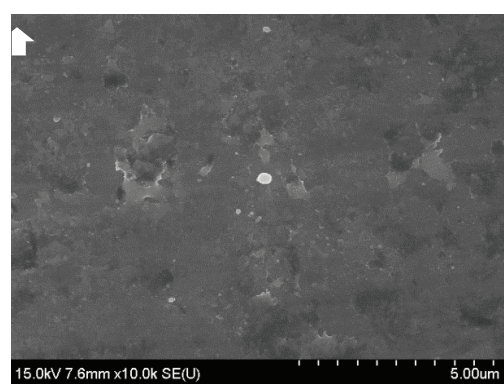

(d) 5 days

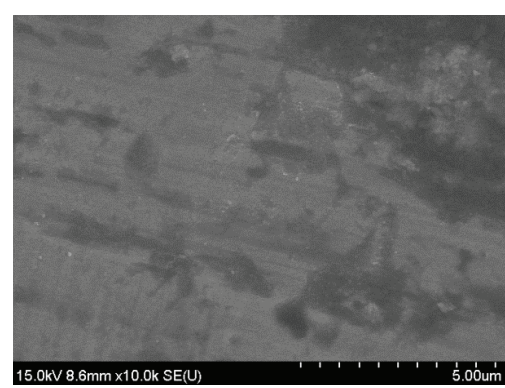

(b) 1 day

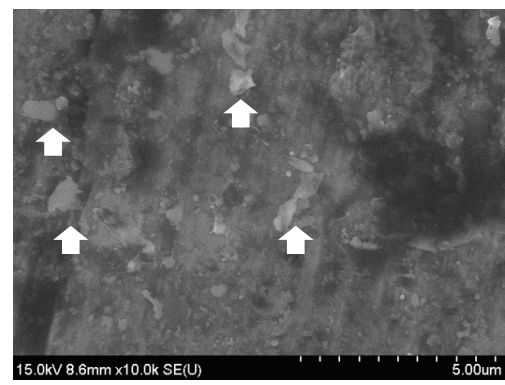

(e) 9 days

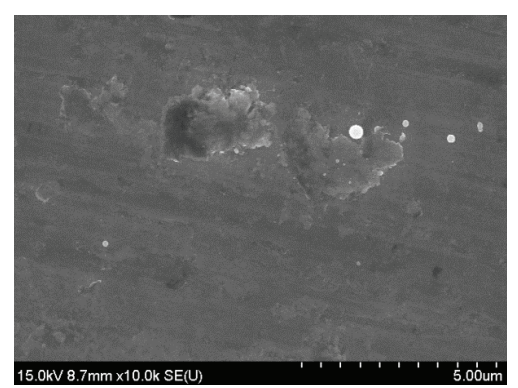

(c) 3 days

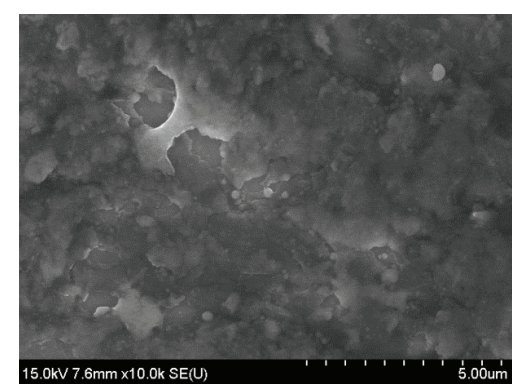

(f) 14 days

FIGURE 3: FESEM images of pristine Mo foil (a) and Mo foils heated in liquid Ga for 1 day (b), 3 days (c), 5 days (d), 9 days (e), and 14 days (f).

(see arrowed area in Figures 1(c) and 1(d)) and aggregates. Particularly, when the heating time was longer than nine days, lumps of aggregates with a size of several $\mu \mathrm{m}$ were easily observed on the Ti foil surface (see arrowed area in Figures 1(e) and 1(f)). In the case of the $\mathrm{Nb}$ foil, the amount of the adhered material also was monotonically increased as the heating time increased. However, the amount of material adhered to the $\mathrm{Nb}$ foils was significantly reduced compared with the Ti foils. When the heating time was increased up to three days, there was little material (in the form of either nanoparticles or aggregates) adhered to the $\mathrm{Nb}$ foil surface (Figures 2(a)-2(c)). After heating for more than five days, nanoparticles were found on the $\mathrm{Nb}$ foil surface, and the number of nanoparticles increased as the heating time was 


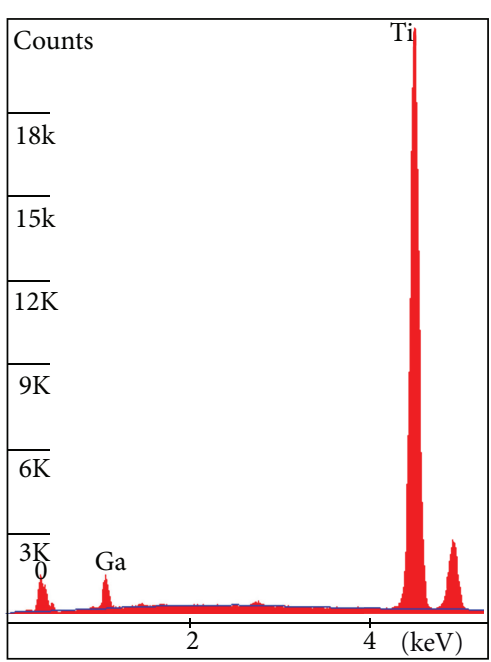

(a)

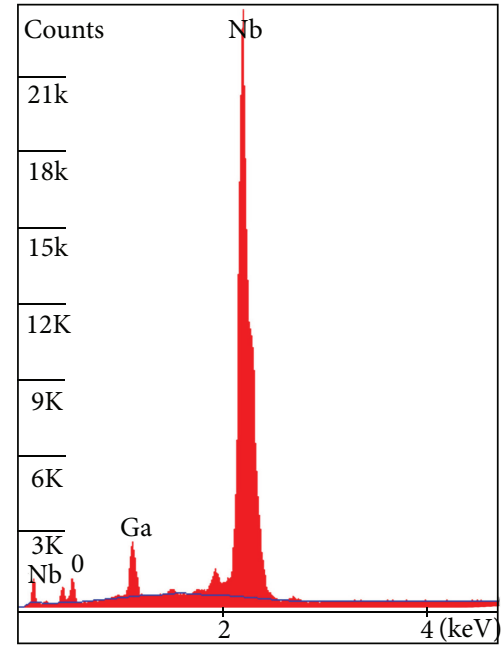

(b)

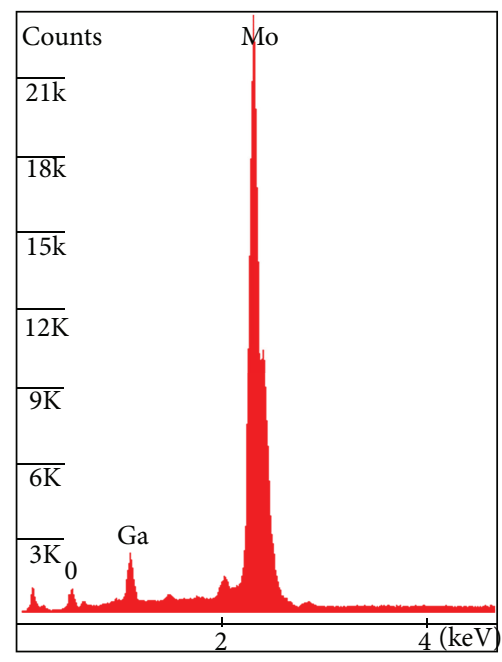

(c)

FIGURE 4: EDS peaks of Ti (a), Nb (b), and Mo (c) foils heated in the liquid Ga.
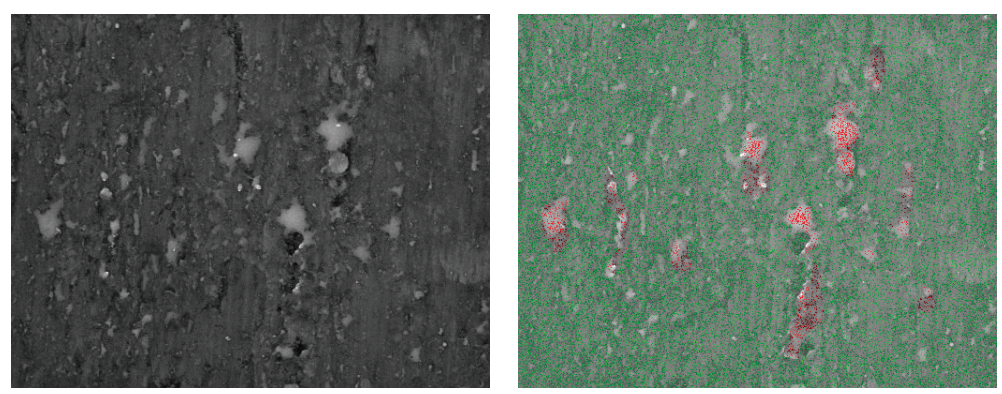

(a) $\mathrm{Ti}$
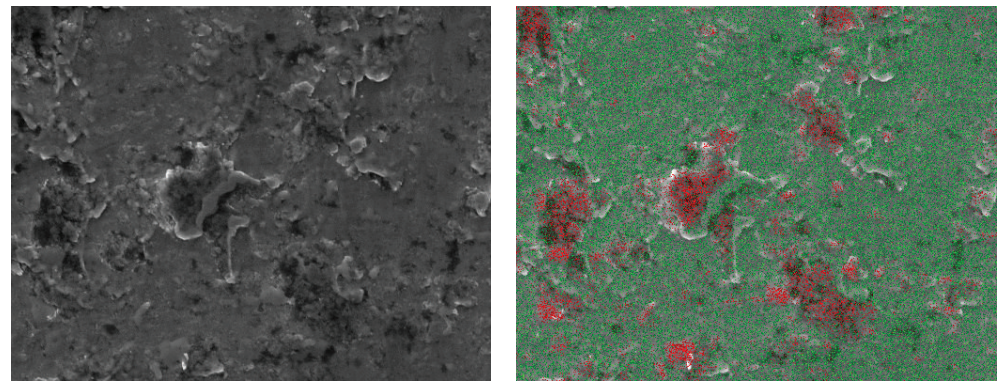

(b) $\mathrm{Nb}$
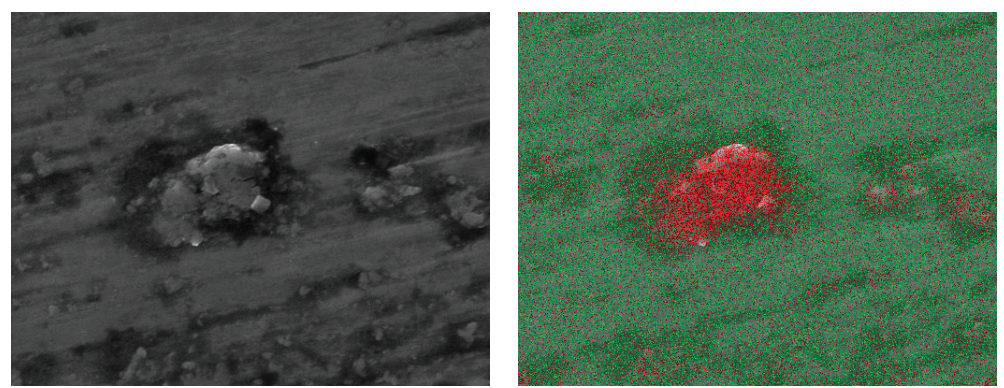

(c) $\mathrm{Mo}$

FIGURE 5: FESEM images and corresponding EDS mapping data of $\mathrm{Ti}(\mathrm{a}), \mathrm{Nb}(\mathrm{b})$, and $\mathrm{Mo}$ (c) foils heated in liquid Ga. 


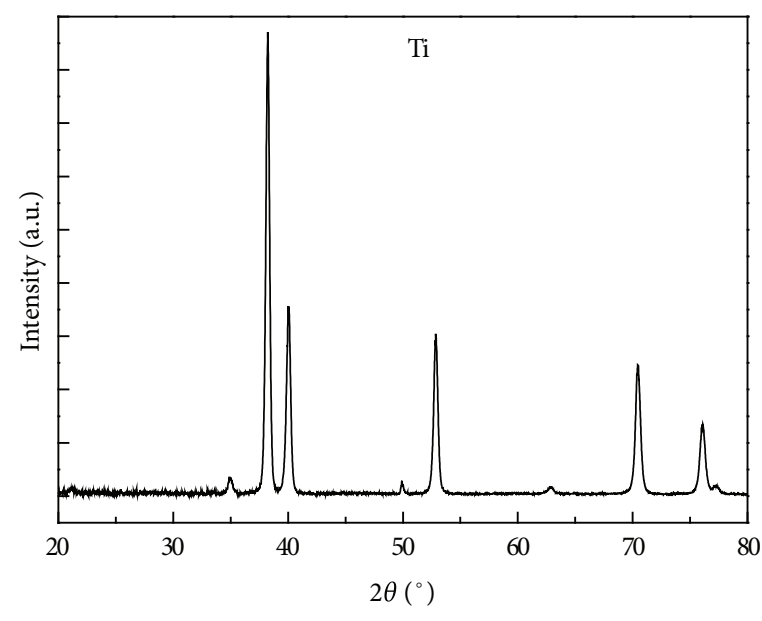

(a)

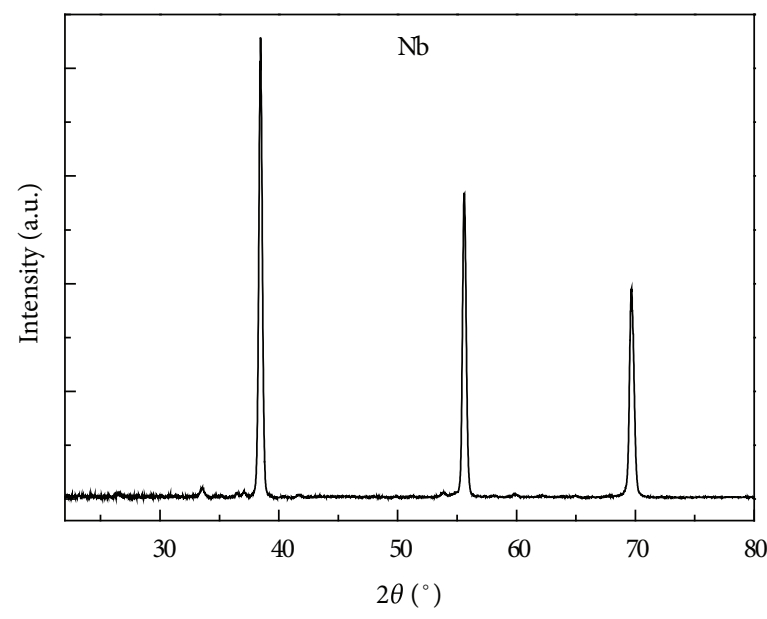

(b)

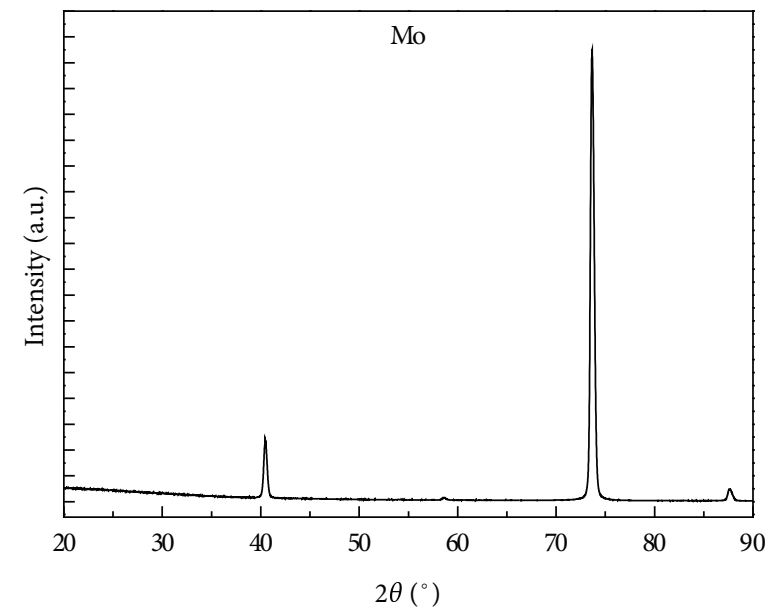

(c)

Figure 6: XRD peaks of Ti (a), Nb (b), and Mo (c) foils heated in liquid Ga.

increased, as shown in Figures 2(d) and 2(e). Aggregates were also observed when the heating time was increased to 14 days (see arrowed area in Figure 2(f)). In the case of the Mo foil, the amount of adhered material was monotonically increased as the heating time increased, similar to the case of $\mathrm{Ti}$ and $\mathrm{Nb}$ (Figure 3). The amount of the adhered material was relatively abundant compared with that of $\mathrm{Nb}$. In addition, the adhesion material in this case appeared mainly in the form of micro/nanoparticles (see arrowed area in Figure $3(\mathrm{e})$ ) while the adhesion material was mainly in the form of aggregates for the Ti foil.

3.2. EDS Analysis. To identify the materials that adhered on the metal foil surfaces, the samples were analyzed using EDS. The EDS peaks measured from the Ti, Nb, and Mo foils after heating in the liquid Ga are shown in Figure 4. All samples exhibited peaks of the elements that compose the pristine foils: Ga peaks with intensities much smaller than those of the former peaks ( $\mathrm{Ti}, \mathrm{Nb}$, and $\mathrm{Mo}$ ), and small oxygen $(\mathrm{O})$ peaks that possibly originated from the metal foil surfaces that were oxidized naturally or via the heating process. In addition, elemental mapping of the $\mathrm{Ti}, \mathrm{Nb}$, and $\mathrm{Mo}$ foils heated in liquid Ga was performed. Figure 5 displays the FESEM images showing the attached Ga on the metal foil surfaces and the corresponding EDS elemental mapping data (green: metal foil, red: attached Ga). This result revealed that a relatively small amount of $\mathrm{Ga}$ was attached to the metal surfaces by heating in the liquid Ga. According to the result of the EDS element analysis, the proportion of Ga was only a few weight percent for the Mo and Nb foils while much larger amount of $\mathrm{Ga}$ was attached to the Ti foil (Table S1). The Nb foil showed the minimum adhesion of $\mathrm{Ga}$ while the $\mathrm{Ti}$ foil exhibited the maximum adhesion of Ga.

3.3. XRD and XPS Analysis. To clarify whether Ga was either physically attached or chemically bonded on the metal foil surfaces, XRD and XPS data were collected and analyzed. The XRD peaks measured from the Ti foil heated in liquid Ga are shown in Figure 6(a). The peaks were centered at $34.94^{\circ}$, $38.21^{\circ}, 40.03^{\circ}, 52.83^{\circ}, 62.83^{\circ}, 70.44^{\circ}, 76.03^{\circ}$, and $77.32^{\circ}$, corresponding to the (100), (002), (101), (102), (110), (103), (112), and (201) planes of pure $\mathrm{Ti}$, respectively. However, no XRD Ga peaks were found. This result indicates that heating in liquid $\mathrm{Ga}$ at $120^{\circ} \mathrm{C}$ for two weeks did not affect the Ti foils, 


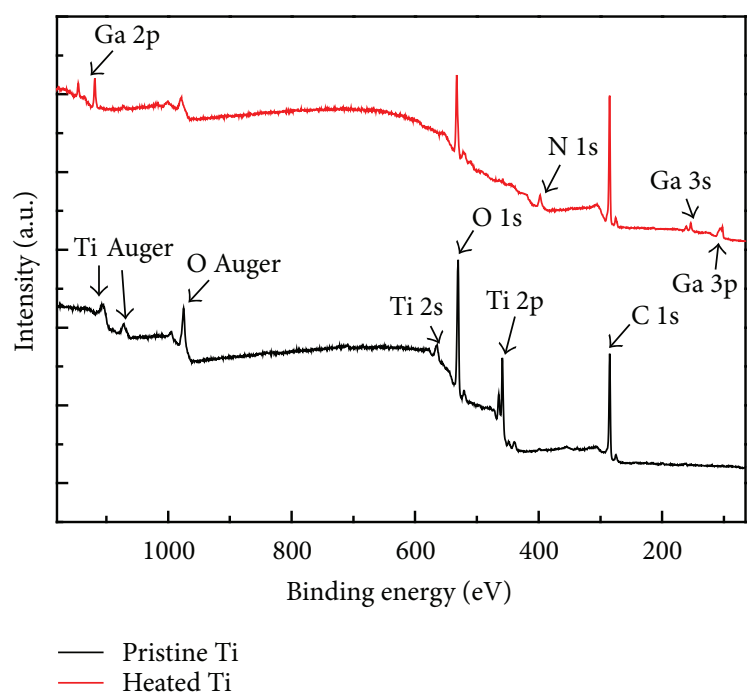

(a)

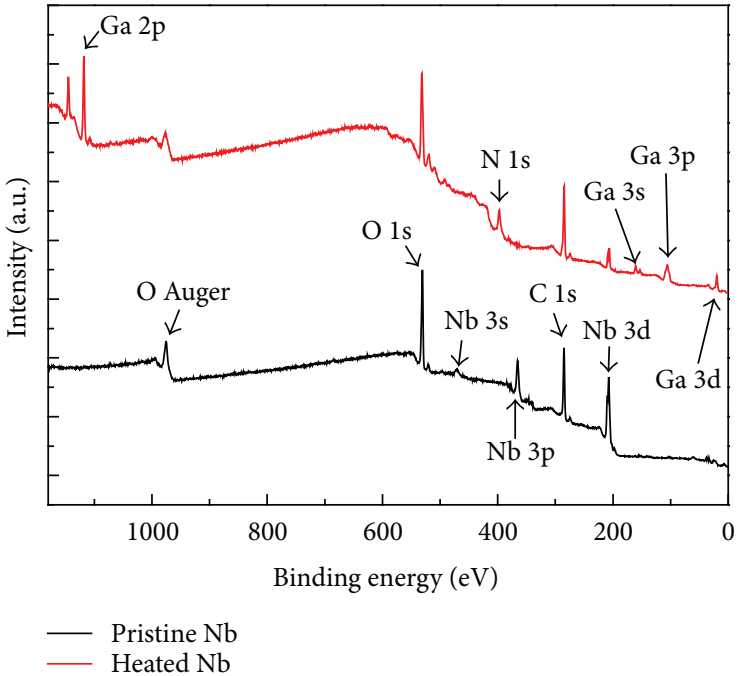

(b)

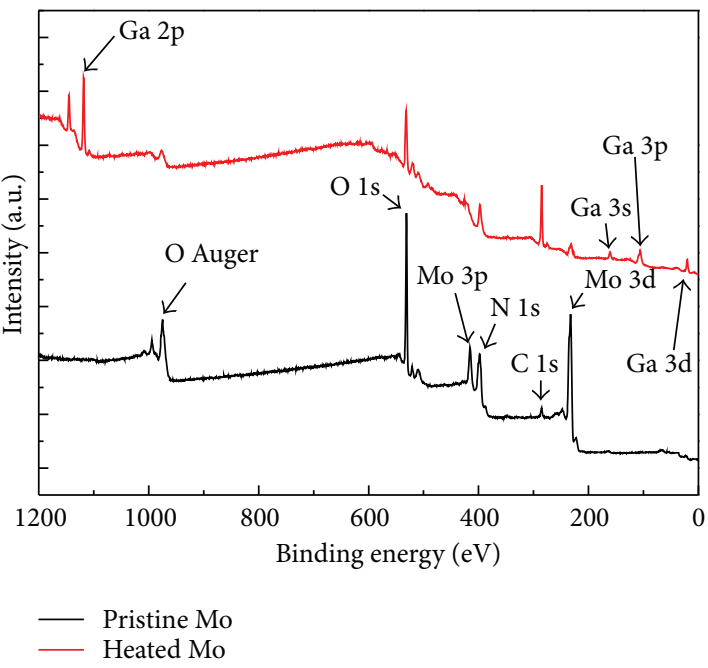

(c)

FIGURE 7: XPS survey spectra of Ti (a), Nb (b), and Mo (c) foils before and after heating in the liquid Ga.

and the amount of Ga that adhered to the Ti foils was too small to be detected by XRD. The Nb and Mo foils exhibited XRD peaks with the same behavior. For the $\mathrm{Nb}$ foil, the XRD peaks were centered at $38.44^{\circ}, 55.59^{\circ}$, and $69.66^{\circ}$, corresponding to the (110), (200), and (211) planes of pure $\mathrm{Nb}$, respectively (Figure 6(b)). Similarly, the XRD peaks of Mo were centered at $40.42^{\circ}, 58.58^{\circ}, 73.61^{\circ}$, and $87.59^{\circ}$, corresponding to the (110), (200), (211), and (220) planes of pure Mo (Figure 6(c)).

The chemical composition changes in the metal foil surfaces were investigated using X-ray photoelectron spectroscopy (XPS). The XPS survey spectra of the Ti, Nb, and Mo foils heated in the liquid Ga are shown in Figure 7. All of the pristine metal foils exhibited their characteristic peaks, a C 1s peak that possibly resulted from a surface contaminant, and the $\mathrm{O}$ peaks that most likely resulted from a natural oxidation. However, all of the XPS peaks of $\mathrm{Ti}$ (such as the Ti 2s, 2p, and Auger peaks) disappeared while the Ga peaks (such as the $2 \mathrm{p}, 3 \mathrm{~s}$, and $3 \mathrm{p}$ peaks) appeared after heating in the liquid Ga (Figure 7(a)). The change in survey spectra of the Ti foil may result from the formation of a thin Ga layer ( $>$ a few $\mathrm{nm}$ ) on the Ti foil surface after the heating in the liquid Ga because these XPS signals originate from the material surface at a depth of only a few $\mathrm{nm}[11,12]$, while the conventional $\mathrm{XRD}$ is able to gather data at a depth of several $\mu \mathrm{m}$ from the material surface due to the difference in the energy of the Xray radiation. In the case of the $\mathrm{Nb}$ and Mo foils, only the small $3 \mathrm{~d}$ peaks of $\mathrm{Nb}$ and Mo remained, and the Ga peaks appeared after heating in the liquid Ga (Figures 7(b) and $7(\mathrm{c})$ ). It appears that Ga layer which adhered to the Ti foils was relatively thicker than that of the $\mathrm{Nb}$ and Mo foils.

The $\mathrm{Ga} 2 \mathrm{p}$ peaks of the $\mathrm{Ti}, \mathrm{Nb}$, and Mo foils were all centered at $\sim 1118$ and $\sim 1145 \mathrm{eV}$, corresponding, respectively, to the typical $2 \mathrm{p}_{3 / 2}$ and $2 \mathrm{p}_{1 / 2}$ peaks of pure $\mathrm{Ga}$ (see Figure $\mathrm{S} 2$ ). This result showed that the $\mathrm{Ga}$ is only physically attached 


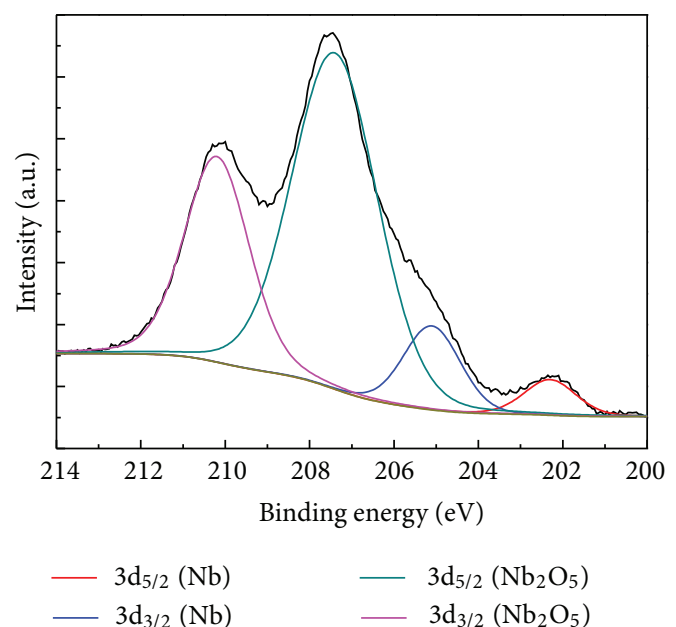

(a)

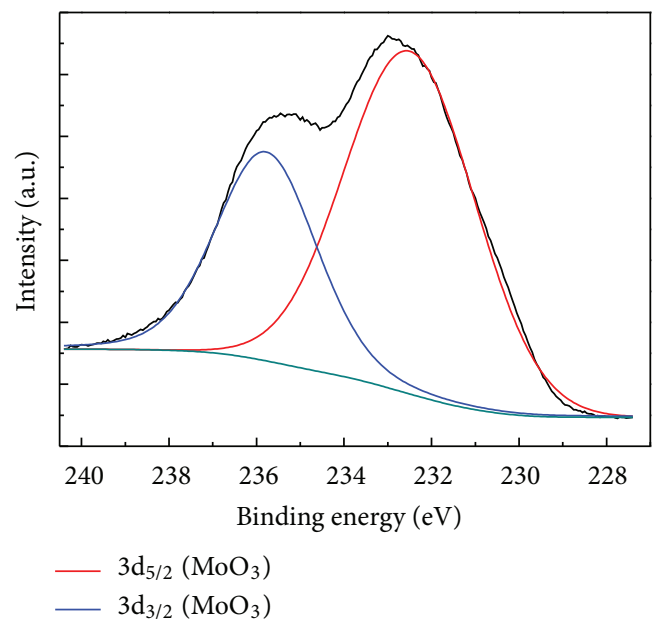

(c)

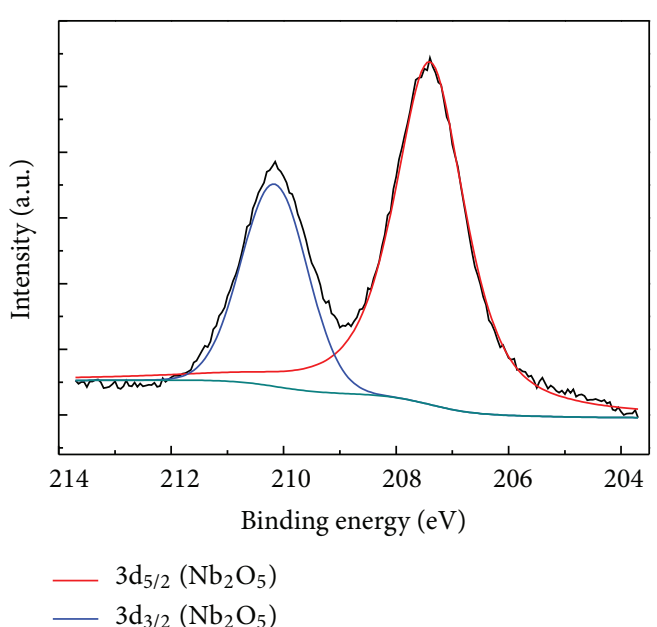

(b)

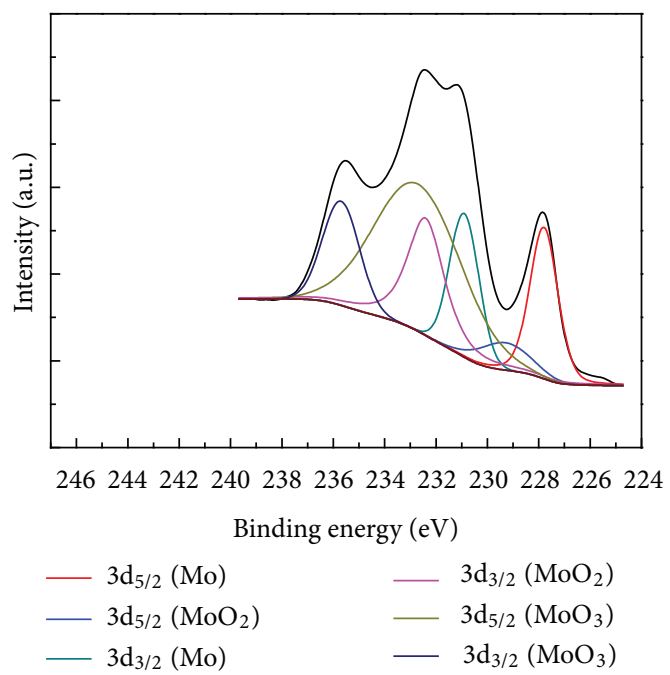

(d)

FIGURE 8: 3d peaks of pristine $\mathrm{Nb}$ foil (a), $\mathrm{Nb}$ foil heated in the liquid $\mathrm{Ga}(\mathrm{b})$, pristine Mo foil (c), and Mo foil heated in liquid Ga (d).

to the metal foil surfaces, with no evidence of any chemical bonding.

However, a chemical change in the metal foil surfaces was observed. For the Ti foil, further analysis could not be carried out because all of the Ti peaks disappeared after heating in the liquid Ga. Detailed analysis of $3 \mathrm{~d}$ spectra was performed for $\mathrm{Nb}$ and Mo. As shown in Figure 8(a), the 3d peak of the pristine $\mathrm{Nb}$ could be deconvoluted into four peaks centered at 202.3, 205.1, 207.4, and $210.2 \mathrm{eV}$, corresponding to the $3 \mathrm{~d}_{5 / 2}$ and $3 \mathrm{~d}_{3 / 2}$ peaks of pure $\mathrm{Nb}$, and the $3 \mathrm{~d}_{5 / 2}$ and $3 \mathrm{~d}_{3 / 2}$ peaks of $\mathrm{Nb}_{2} \mathrm{O}_{5}$, respectively. This result means that the surface of the $\mathrm{Nb}$ foil consisted of pure $\mathrm{Nb}$ and its natural oxide. In contrast, the two peaks centered at 202.3 and $205.1 \mathrm{eV}$ disappeared, and only two other peaks centered at 207.4 and $210.2 \mathrm{eV}$ remained after the heating in the liquid $\mathrm{Ga}$, which implies that the material was transformed into a fully oxidized surface (Figure $8(\mathrm{~b})$ ). On the other hand, the $3 \mathrm{~d}$ peak of the pristine Mo could be deconvoluted into two peaks centered at 232.7 and $235.8 \mathrm{eV}$, respectively, corresponding to the $3 \mathrm{~d}_{5 / 2}$ and $3 \mathrm{~d}_{3 / 2}$ peaks of $\mathrm{MoO}_{3}$, which is one of the oxide forms of Mo (Figure 8(c)). Interestingly, the Mo foil surface appeared to be reduced after heating in liquid Ga. After heating in the liquid $\mathrm{Ga}$, the shape of the Mo 3d peak became more complicated, as shown in Figure $8(\mathrm{~d})$. The peak could be deconvoluted into six peaks including the former two peaks and peaks centered at 227.8, 229.3, 230.9, and $232.5 \mathrm{eV}$, corresponding to the $3 \mathrm{~d}_{5 / 2}$ peak of pure Mo and $\mathrm{MoO}_{2}$ and the $3 \mathrm{~d}_{3 / 2}$ peaks of pure $\mathrm{Mo}$ and $\mathrm{MoO}_{2}$, respectively. This result indicated that a portion of the $\mathrm{Mo}(\mathrm{VI})$ was reduced to $\mathrm{Mo}(0)$ or $\mathrm{Mo}(\mathrm{IV})$.

\section{Conclusions}

This work investigated the effect of liquid $\mathrm{Ga}$ on $\mathrm{Ti}, \mathrm{Nb}$, and Mo foils at temperatures higher than the melting point of $\mathrm{Ga}$. After the metal foils were heated in the liquid $\mathrm{Ga}$ at $120^{\circ} \mathrm{C}$, a small amount of $\mathrm{Ga}$ remained on the metal foil surfaces even after several washing steps. Among the metal 
foils used in this study, the $\mathrm{Nb}$ foil showed the minimum adhesion of $\mathrm{Ga}$ while the $\mathrm{Ti}$ foil exhibited the maximum adhesion of $\mathrm{Ga}$. From the perspective of separation of $\mathrm{Ga}$ from the metal foils, we can conclude that $\mathrm{Nb}$ is the most attractive material among the three tested. In contrast, from the perspective of the chemical composition change, the $\mathrm{Nb}$ foil surfaces appeared to be oxidized after heating in the liquid Ga while the Mo foil surfaces were reduced. In conclusion, the conventional $\mathrm{Nb}$ encapsulation material of $\mathrm{Ga}$ exhibited the least Ga adhesion, a superior property, but Mo also could be used as the encapsulation material for Ga due to its chemical resistance against oxidation during the heating, even though a relatively larger amount of Ga was observed to adhere to its surface compared with $\mathrm{Nb}$.

\section{Acknowledgment}

This work was supported by the Nuclear R\&D Program of the National Research Foundation (NRF) funded by the Ministry of Education, Science, and Technology (MEST), Republic of Korea.

\section{References}

[1] C. Naidoo, T. N. van der Walt, and H. G. Raubenheimer, "Cyclotron production of ${ }^{68} \mathrm{Ge}$ with a $\mathrm{Ga}_{2} \mathrm{O}$ target," Journal of Radioanalytical and Nuclear Chemistry, vol. 253, no. 2, pp. 221-225, 2002.

[2] P. J. Pao, D. J. Silvester, and S. L. Waters, "A new method for the preparation of ${ }^{68} \mathrm{Ga}$-generators following proton bombardment of gallium oxide targets," Journal of Radioanalytical Chemistry, vol. 64, no. 1-2, pp. 267-272, 1981.

[3] C. Loc'h, B. Maziere, D. Comar, and R. Knipper, "A new preparation of germanium 68," International Journal of Applied Radiation and Isotopes, vol. 33, no. 4, pp. 267-270, 1982.

[4] G. E. Meinken, S. Kurczak, L. F. Mausner, K. L. Kolsky, and S. C. Srivastava, "Production of high specific activity ${ }^{68} \mathrm{Ge}$ at Brookhaven National Laboratory," Journal of Radioanalytical and Nuclear Chemistry, vol. 263, no. 2, pp. 553-557, 2005.

[5] F. M. Noriter, M. E. Fassbender, M. Dejohn et al., "Targetry at the LANL $100 \mathrm{MeV}$ isotope production facility: lessons learned from facility commissioning," in Americas Nuclear Energy Symposium, LA-UR-04-6421, October 2004.

[6] L. R. Kelman, W. D. Wilkinson, and F. L. Yaggee, "Resistance of materials to attack by liquid metals," Argonne National Laboratory Report ANL-4417, 1950.

[7] M. H. Kamdar, "Embrittlement by liquid metals," Progress in Materials Science, vol. 15, no. 4, pp. 289-374, 1973.

[8] M. S. Berridge, K. W. Voelker, and B. Bennington, "High-yield, low-pressure $\left[{ }^{18} \mathrm{O}\right]$ water targets of titanium and niobium for F-18 production on MC-17 cyclotrons," Applied Radiation and Isotopes, vol. 57, no. 3, pp. 303-308, 2002.

[9] L. C. A. Sumiya and V. Sciani, "Evaluation of irradiation parameters of enriched ${ }^{124} \mathrm{Xe}$ target for ${ }^{123} \mathrm{I}$ production in cyclotrons," Applied Radiation and Isotopes, vol. 66, no. 10, pp. 1337-1340, 2008.

[10] R. W. M. Kwok, "XPS Peak Fitting Program for WIN95/98 XPSPEAK version 4.1," 2000.

[11] C. Y. Tang, Y. N. Kwon, and J. O. Leckie, "Probing the nano- and micro-scales of reverse osmosis membranes-a comprehensive characterization of physiochemical properties of uncoated and coated membranes by XPS, TEM, ATR-FTIR, and streaming potential measurements," Journal of Membrane Science, vol. 287, no. 1, pp. 146-156, 2007.

[12] B. Berini, N. Keller, Y. Dumont et al., "Reversible phase transformation of $\mathrm{LaNiO}_{3-x}$ thin films studied in situ by spectroscopic ellipsometry," Physical Review B, vol. 76, no. 20, Article ID 205417, 9 pages, 2007. 

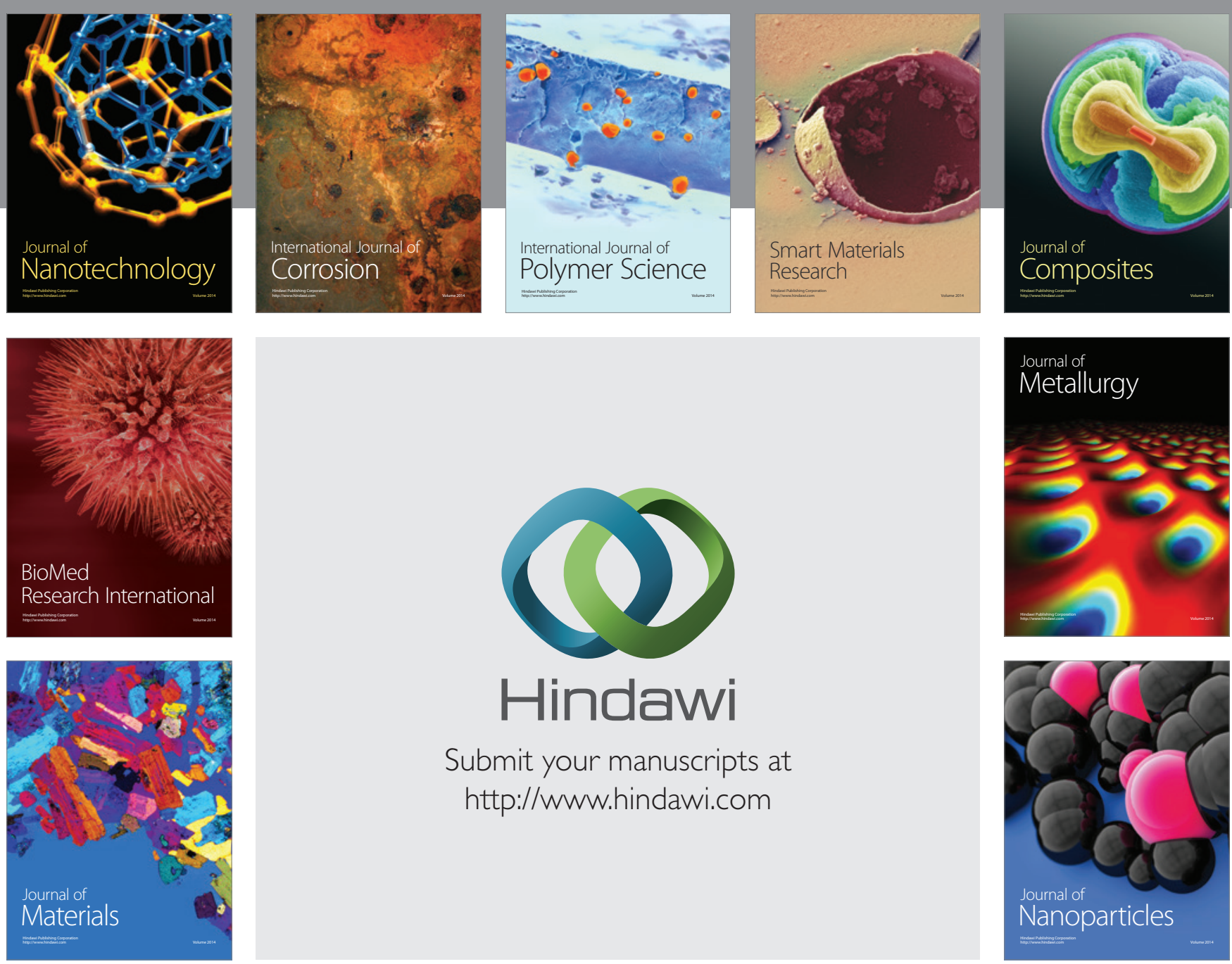

Submit your manuscripts at http://www.hindawi.com
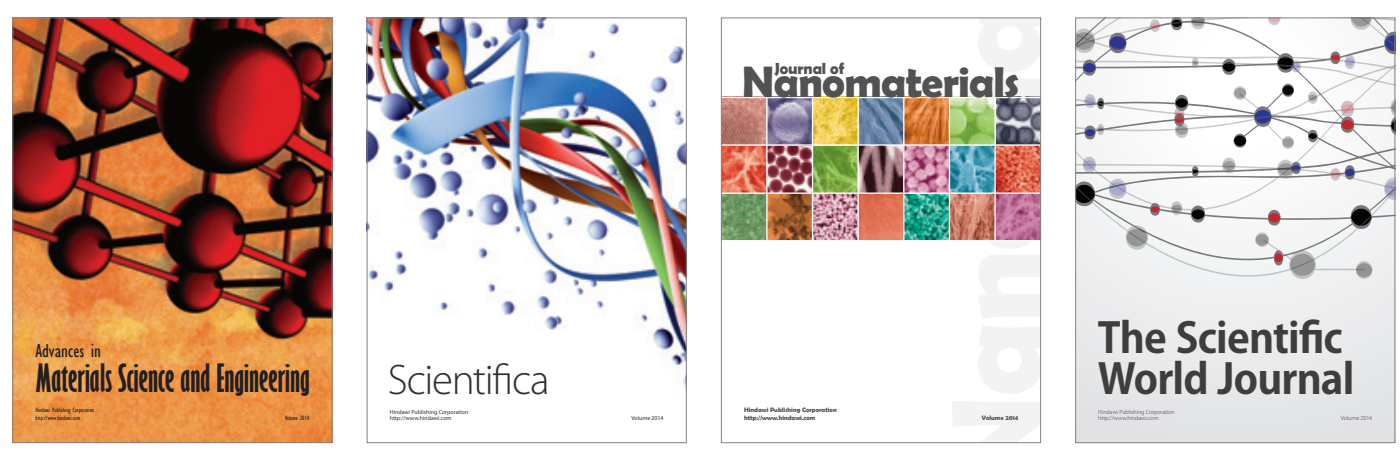

\section{The Scientific World Journal}
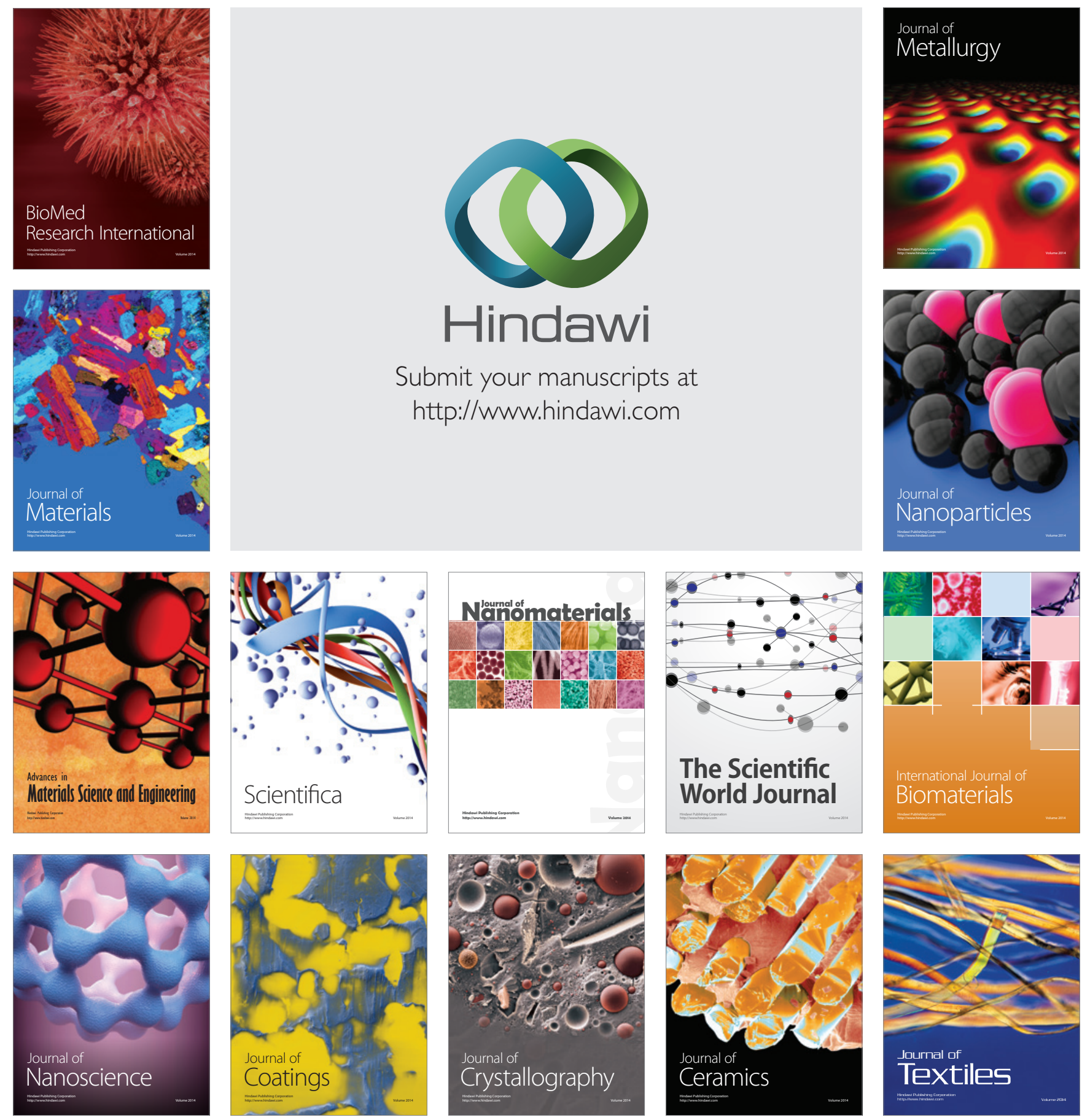